22. Heiner DC 1984 Significance of immunolgobulin G subclasses. Am J Med 76:1-6

23. Riesen WF, Skvaril F, Braun DB 1976 Natural infection of man with group A streptococci: levels; restriction in class, subclass and type; and clonal appearance of polysaccharide-group-specific antibodies. Scand J Immunol 5:383390

24. Yount WJ, Dorner MM, Kunkel HG, Kabat EA 1968 Studies on human antibodies V1 selective variations in subgroup composition and genetic markers. J Exp Med 177:633-646

25. Oxelius V-A 1974 Chronic infections in a family with hereditary deficiency of IgG2 and IgG4. Clin Exp Immunol 17:19-27

26. Hammarstrom L, Persson MAA, Smith CIE 1985 Immunoglobulin subclass distribution of human anti-carbohydrate antibodies: aberrant pattern in IgAdeficient donors. Immunology 54:821-826

\title{
Announcements
}

\author{
Annual Meeting
}

The American Pediatric Society and The Society for Pediatric Research announce the abstract deadline for the 1987 Annual Meeting (April 27-May 1, Disneyland Hotel, Anaheim, CA) has been set as December 3, 1986.

For further information contact: SPR-Debbie L. Wogenrich, The Society for Pediatric Research, Department of Pediatrics, UNM School of Medicine, Albuquerque, NM 87131 (505)277-6629 or APS-Dr. Audrey K. Brown, Secretary-Treasurer, Department of Pediatrics, Box 49, SUNY, Health Sciences Center at Brooklyn, 450 Clarkson Avenue, Brooklyn, NY 11203, (718)270-1692.

\section{Pediatric Hematology-Oncology Examination}

The Sub-Board of Pediatric Hematology-Oncology of the American Board of Pediatrics will administer its next certifying examination on Friday, July 10, 1987.

The following criteria must be met to be eligible to sit for the examination: 1. Certification by the American Board of Pediatrics. 2. Physicians who entered pediatric hematology-oncology training prior to January 1, 1986, may apply for admission to the examination on the basis of their completion of two years of subspecialty residency training in pediatric hematology-oncology. 3. Verification of training and recommendation by Program Director.

Each application will be considered individually and must be acceptable to the Sub-Board of Pediatric Hematology-Oncology.

Registration for this examination will extend from October 1, 1986, to January 31, 1987. Requests for applications received prior to the opening of registration will be held on file until that date, at which time application materials will be sent to those who have requested them.

The application fee for the examination is $\$ 800$ ( $\$ 275$ processing and evaluating fee plus $\$ 525$ examination fee). Candidates not approved to take the examination will be refunded the $\$ 525$ examination fee. The processing and evaluating fee will be retained.

Please direct inquiries to the American Board of Pediatrics, 111 Silver Cedar Court, Chapel Hill, NC 27514-1651. Telephone (919) 929-0461. 